\title{
Estrategias de reterritorialización en la poesía amazónica contemporánea ${ }^{1}$ Reterritorialization Strategies in Contemporary Poetry Amazon
}

\author{
Claudia Rodríguez Monarca \\ Universidad Austral de Chile \\ claudiar@uach.cl
}

\begin{abstract}
El artículo propone una mirada relacional de un corpus acotado de poemas de escritores amazónicos de distintas procedencias. La hipótesis de este trabajo es que a partir de la experiencia y la conciencia de desterritorialización y desplazamiento, los sujetos poéticos encuentran claves y estrategias de reterritorialización, como una forma de resistencia cultural. La reterritorialización estaría operando mediante dos procesos: la recuperación intracultural (reapropiación de su espacio territorial, cultural y simbólico) y el agenciamiento intercultural (apropiación del espacio ajeno, por parte del sujeto migrante). Estos procesos funcionan como instancias de validación de una identidad colectiva y generan actitudes enunciativas, por medio de diversas estrategias que hemos identificado como la reescritura de la (micro) historia o de acontecimientos, la apelación a lo sagrado, la rememorización y la apropiación del lenguaje (vinculada a las condiciones lingüísticas). El repertorio considera a poetas amazónicos contemporáneos, indígenas y no indígenas, de Colombia, Ecuador, Perú y Bolivia.
\end{abstract}

Palabras clave: Desterritorialización, reterritorialización, poesía amazónica, recuperación intracultural, agenciamiento intercultural.

The article proposes a relational look of a corpus limited of poems of Amazonian writers from different origins. The hypothesis of this work is that it is based on the experience and conscience of deterritorialization and displacement, the poetic subjects are keys and reterritorialization strategies, as a form of cultural resistance. The reterritorialization would be operating through two processes: the intracultural recovery (reappropriation of their territorial and cultural space) and the intercultural agency (appropriation of other people's space, by the migrant subject). These processes operate as instances of a collective identity validation and generate enunciative attitudes, through various strategies that we have identified as: (micro) rewriting history or events, appeal to the sacred, the rememorizacion and the appropriation of the language (linked to linguistic conditions). The repertoire is considered contemporary to Amazon, indigenous and non-indigenous poets of Colombia, Ecuador, Peru and Bolivia.

Keywords: Deterritorialization, reterritorialization, Amazon poetry, intracultural recovery, intercultural agency.

1 El artículo se adscribe al proyecto Fondecyt No 1141007 "Reterritorialización en las literaturas andino-amazónicas: poéticas y enunciaciones heterogéneas en confluencia", del que soy investigadora responsable. 


\section{Introducción: si el río suena es porque voces trae²...}

Yo soy un río,/ voy bajando por/ las piedras anchas, voy bajando por/ las rocas duras,/ por el sendero dibujado por el/ viento.// Hay árboles a mi alrededor sombreados/ por la lluvia.

El río, 1960. Javier Heraud

Yo soy el hombre de la selva, perfume, / cántigo /y amor, pero encendido de relámpagos, pero rugiendo de huracanes. Yo soy un río de pie.

"Canto al hombre de la selva", 1964. Raúl Otero Reiche

No es arbitraria la elección de estos epígrafes, la imagen y la identificación del río con los sujetos poéticos constituyen, sin lugar a dudas, la filiación que permea la literatura amazónica. Los dos poetas Heraud y Otero Reieche, de Perú y Bolivia, respectivamente, son figuras tutelares e inaugurales de una poética moderna que se asienta y navega por los afluentes del amazonas, sin cruzar muchas veces la muralla verde de sus fronteras. Es por ello que, desde nuestro contexto chileno, y con la distancia que nos separa, el territorio amazónico es visualizado como un espacio exótico, de selva exuberante (el pulmón del planeta, dirá esa manida frase) y de culturas aborígenes monolingües, bárbaras e incluso antropófagas. La televisión fue la primera en traernos esas imágenes ${ }^{3}$. Salvo algunas excepciones, las representaciones que tenemos de la Amazonía siguen reproduciendo ese exotismo. Un acercamiento desde las propias producciones culturales es un buen comienzo para borrar esas murallas y penetrar, desde el lenguaje, la selva (o)culta.

El artículo propone una mirada relacional de un corpus acotado de poemas de escritores amazónicos de distintas procedencias culturales, nacionales, indígenas y no indígenas (colonos y ribereños), con distintos grados de acercamiento hacia otras culturas y tradiciones literarias, que evidencian la heterogeneidad de lo que se ha llamado en plural, las literaturas amazónicas; y que, sin embargo, nos invitan a leer dialógicamente desde sus confluencias o coincidencias. Uno de los tópicos convergentes es la problemática de

\footnotetext{
2 Este juego de palabras hace alusión no solo al refrán popular sino también al título de un libro emblemático en los estudios de la región amazónica, Amazonía: El río tiene voces, de Ana Pizarro, de 2009.

3 La telenovela brasilera Pantanal en el año 90 inaugura el paisaje amazónico, y luego el 2007 el antropólogo Ricardo Astorga presenta "La ruta de la Amazonía", una serie documental de varios capítulos que muestran su travesía por el río, desde una perspectiva un tanto incrédula, exógena y distante; luego el 2013 regresa con otro programa, "La Odisea", de factura mediática, donde, desde una perspectiva más empática y cercana, se imbuye en el mundo de las culturas amazónicas, incursionando y participando incluso en una ceremonia ritual de ayahuasca.
} 
la desterritorialización, entendida como un fenómeno gradual de pérdidas de elementos culturales, naturales e identitarios, partiendo por el propio territorio que se ve modificado, producto del sistema económico extractivo y depredador, que hace que diez mil hectáreas de la Amazonía se pierdan diariamente y con ellas desaparezcan flora y fauna, y dejen de figurar para siempre en los paisajes verdes de la región ${ }^{4}$. Pero el sujeto de ese hábitat transformado no es el único que vive la pérdida, también la sufre el migrante que se aleja de ese espacio amado, de la infancia y al que añora.

La hipótesis de este trabajo es que a partir de la experiencia y la conciencia de desterritorialización y desplazamiento, los sujetos poéticos encuentran claves y estrategias de reterritorialización, como una forma de resistencia cultural. La reterritorialización, siempre en el plano de la escritura, estaría operando mediante dos procesos: la recuperación intracultural (reapropiación de su espacio territorial, cultural y simbólico) y el agenciamiento intercultural (apropiación del espacio ajeno, por parte del sujeto migrante).

Los lugares de procedencia de los poetas del corpus y el marco en el que delimitamos el emplazamiento geográfico corresponden a la Amazonía de Bolivia, Perú, Ecuador y Colombia, lo que nos permite cartografiar, acotar y situarnos en un área significativa de esta macrorregión (Gastó 1993), entendida como un área cultural panamazónica. Varios son los poetas que dan cuenta de esta especie de patria mayor, de esta hermandad, como el peruano Percy Vilches y el boliviano Nicomedes Suárez Araúz. El primero señala en una entrevista que la Amazonía es "un subcontinente fluvial", es decir, no una Amazonía regional, sino aquella que es todo un territorio... no somos ni una región ni un país, sino todo un continente". Por su parte, Nicomedes Suárez alude a esta Amazonía trasfronteriza, a estas "fronteras vivas" (al decir de Guallart), en el poema "Elegía del Alba":

La lluvia de Manaus, Brazil, / es la lluvia de Riberalta, Bolivia,/ es la lluvia de Santa Ana, mi pueblo,/ es la lluvia de Iquitos, Perú,/ la lluvia de Leticia, Colombia.// Hilos de agua que caen sobre el polvo,/ juntos, agua y tierra,/ arcilla somos para ya no separamos jamás,/ y no hay distancia entre nosotros/ y los grandes árboles / que mueren en la noche.

\footnotetext{
4 Muy alejados de lo que Philippe Descola propone en La selva culta como los "criterios del buen vivir", entre ellos la subexplotación de los recursos y la productividad del sistema; por el contrario, la llegada de la modernidad a la Amazonía traería consigo modificaciones drásticas de los modos de subsistencia y del medio ambiente. Muchos son los estudios que corroboran los daños colaterales que trae la explotación de los recursos naturales, como el libro de Michael Brown (1984), Una Paz Incierta, que alude al cambio cultural que ha provocado la construcción de la carretera por la relativa facilidad de transporte, promoviendo la deforestación, para una agricultura de monocultivo (generalmente de arroz) (46-51). Jesús San Román, en Perfiles Históricos de la Amazonía Peruana señala que lo mismo sucede con la actividad petrolera que fue negativa para la producción agrícola. "El boom petrolero no solo arrastró a la población rural a las ciudades sino que arrasó con la producción agrícola" (1994: 253).
} 
El poeta tiene conciencia que lo que las fronteras políticas demarcan y separan, el río serpenteante las atraviesa y las une en un cauce natural. Si bien las características geográficas cobran protagonismo, también la cosmovisión y la cosmopercepción ${ }^{5}$ son fundamentales para la comprensión del universo panamazónico. Stéfano Varese en su libro La sal de los cerros (1968) señala que "en contraste con el antropocentrismo euroamericano (de larga fecha en la herencia cultural judeocristiana), los pueblos indígenas durante milenios construyeron cosmologías cosmocéntricas y policéntricas basadas en la lógica de la diversidad y la reciprocidad". Es decir, los principios de diversidad (biocultural), de reciprocidad (social y cósmica) y la complementariedad, son las bases de la construcción de una nueva utopía de acuerdo con la cosmopercepción amazónica, que refleja los modos de existencia posibles, donde el sentir y el saber indígena ponen en jaque una supuesta única manera universal de pensar y entender el mundo; este sentipensar con la tierra (Arturo Escobar, 2014) que implica "co-razonar", pensar desde el corazón y desde la mente. El ser amazónico más que una esencia es la construcción y asunción de una mística particular, como sostiene Nicomedes Suárez (2014), desde una reflexión metatextual:

Ser amazónico, como persona y escritor, trasciende el hecho de haber nacido y crecido en ese cautivador confín geográfico. Implica asumir la mística de una patria -que como todas es real e imaginaria-, en este caso, la mística de la patria de las aguas (en la bella frase de Thiago de Mello), la cual, trascendiendo fronteras políticas, restaura la continuidad de los ríos, la floresta, las sabanas, y las sierras (100).

\section{Desde la selva impenetrable a la visibilización de la literatura amazónica}

Referirse a la poesía amazónica supone el reto de la delimitación de varios criterios que tienen que ver con coordenadas espaciales, temporales, estéticas, lingüísticas, sociohistóricas, culturales y nacionales. No obstante, un punto de confluencia desde las distintas regiones y países es que ha sido históricamente incomprendida y marginada por el centralismo de las grandes urbes. La propia antropología reconoce que desde el siglo XVIII la selva fue concebida, en términos generales, como una "región inepta para la civilización", en contraste con la región de los Andes, al menos propicia para un eventual progreso o desarrollo. Margarita Serje (1999) ha señalado que "Allende la cordillera Oriental, la exuberante vegetación verde de la Amazonía era un territorio sin historia donde campeaba la 'barbarie', donde los hombres -aún los 'racionales'- caían, sometidos por la ley de la selva, a la condición humana más abyecta o al imperio de los instintos". Pineda Camacho (2005) lleva esta reflexión al ámbito literario al referirse a La vorágine, de José Estasio Rivera, "cuando, en 1924, fue publicada La vorágine,

5 Concepto en contraposición a "cosmovisión", usado por José Luis Ayala en su Diccionario de la Cosmopercepción Andina y que intenta ampliar el entendido de la relación que el hombre andino posee con el universo. 
los letrados bogotanos apenas pudieron comprenderla y fue leída como el eco de una naturaleza salvaje donde los hombres se contagiaban -en una especie de mimesis- de la misma condición salvaje". Esta fue la tónica durante mucho tiempo no solo de los letrados y críticos colombianos; la literatura amazónica no existió a los ojos de la crítica oficial, vinculada a la academia y al canon, en ninguno de los países que afiataban sus literaturas nacionales. Este aspecto se ha ido revirtiendo gracias a la investigación generada en esos mismos espacios, primero por antropólogos como Stefano Varese y Hugo Niño, y luego por escritores amazónicos e investigadores, como los bolivianos Homero Carvalho y Nicomedes Suárez Araúz, los peruanos Manuel Marticorena, Ricardo Virhuez, Roger Rumrill, Raúl Bardales, María Chavarría y Manuel Cornejo; Ios colombianos Miguel Rocha Vivas, Beatriz Alzate, Juan Álvaro Echeverri, Roberto Pineda Camacho, Fernando Urbina y Juan Carlos Galeano, entre otros.

Dedicarle su tiempo a profundizar e investigar las culturas y literaturas amazónicas supone a priori su existencia. El poeta y crítico boliviano Homero Carvalho (2013) se permite esa pregunta "¿existe una literatura amazónica (boliviana)?" (21) o mejor aún, podemos agregar, ¿existe un sistema literario amazónico? ¿Cuáles serían sus características y en qué radicaría su particularidad?6. Si al conjunto de obras, poéticas y autores, sumados al contexto de producción y recepción, lo entendemos como un sistema poético que demanda ciertas condiciones o requisitos para su funcionamiento y posterior afianzamiento, mediante la consolidación de un sistema de preferencias, podemos entonces colegir que una literatura (pan)amazónica está en proceso de constitución. Y ello no por falta de un corpus importante de autores, sino más bien por la de un renovado corpus crítico con el cual dialogar y que estudie e investigue con rigurosidad las poéticas en torno a estas literaturas particulares. Tampoco es significativo el corpus metatextual (individual y colectivo) que ayude a comprender la cultura, asumiendo una tarea intelectual que ponga en crisis el paradigma epistemológico occidental y que sincere el espacio desde donde se piensa. Tanto la producción literaria como la crítica han tendido a ver esta poesía desde los marcos de las literaturas nacionales e, incluso, muchas veces clasificarla con parámetros similares. Manuel Marticorena, afanoso estudioso, recopilador y especialista en literatura amazónica de Iquitos, ha propuesto en su libro Proceso de la Literatura Amazónica Peruana (2009) un criterio cronológico de periodización inspirado en el texto crítico de Carlos García Bedoya, Para una periodización

\footnotetext{
6 Varios críticos y especialistas postulan que la particularidad, dentro de la heterogeneidad de esta producción, estaría en la herencia cultural indígena como fuente valiosa de recreación y creación. Roger Rumrril (2011), escritor y estudioso de la literatura amazónica peruana, reconoce que "las raíces y las fuentes de la cultura y el arte amazónicos son indígenas. La literatura, la música, la danza, la pintura y otras expresiones de la cultura y el arte reflejan y traducen esta impronta indígena". En una línea similar Ricardo Virhuez (2011) ha señalado que la literatura oral (indígena) puede ser el mejor ejemplo para la construcción del cuento moderno; esta, "vitalización del cuento moderno a partir de la narrativa oral amazónica" (Espino, 2011: 48). Por su parte, el escritor boliviano Homero Carvalho dirá: "existe una cultura que está definida tanto por la cosmovisión como por el lenguaje de las etnias que la habitan, que han fijado una manera de pensar y de sentir el universo y la vida y que se expresa en la mitología, en la música, en las tradiciones orales, en las costumbres, en el lenguaje común y, por supuesto, en la literatura" (2013: 21).
} 
de la literatura peruana. Marticorena, atendiendo a la particularidad amazónica, replantea los períodos que van desde la Relación del Descubrimiento del Famoso río Grande de las Amazonas (1542) de Fray Gaspar de Carvajal, hasta los autores novísimos aparecidos el 2009. Las publicaciones de estudios críticos y antologías de cuentos o poéticas tienden a estar demarcadas por la variable de literaturas nacionales o regionales, sesgo frecuente que Ramón Rocha Monroy reconoce como una "crítica aduanera". Hay algunas excepciones, como la antología Más aplausos para la lluvia. Antología de poesía amazónica reciente (2012), del estudioso norteamericano Jeremy Larochelle, que reúne a escritores de la cuenca amazónica y a textos de vertiente ecopoética.

A pesar de un exiguo corpus crítico académico de la literatura amazónica, reconocemos que hay una vasta tarea de recopilación, principalmente de la tradición oral y de la narrativa amazónica realizada por los propios escritores. De la mano de la recopilación está la divulgación de estos materiales. Se destaca, en este sentido, el trabajo sistemático que viene realizando la Asociación Cultural Javier Heraud, de Iquitos, de considerable influencia y llegada a los establecimientos educativos para la promoción y animación a la lectura de autores amazónicos, guiada principalmente por los escritores Armando Almeida y Manuel Marticorena.

La maduración de una reflexión poética metatextual emerge con un repertorio significativo de escritores que están trabajando en la construcción de un nuevo lenguaje que contribuye al sentido de pertenencia y a su imaginario literario, y que se instala de modo dialógico y transdiscursivo frente a las otras culturas en contacto. Esto es fácil de rastrear en la Amazonía peruana y boliviana7. En Perú, particularmente en la zona de Loreto, lo notamos en los escritores que conforman a comienzos de los 80 el grupo Urcututur, que nace en los pasillos de la Universidad Nacional de la Amazonía de Perú, integrado por Carlos Reyes Ramírez, Percy Vilchez y Ana Varela, y que en 1983

7 En la Amazonía ecuatoriana no existe hasta ahora un corpus significativo de autores amazónicos, salvo algunas excepciones, que constituyan un sistema literario propio, por lo que no hay una reflexión metatextual que permita tomar conciencia de una maduración de sus poéticas. Por su parte, la gran producción literaria de Colombia se ha centrado más en la producción indígena dialógica de todas las regiones (como las antologías de Miguel Rocha), que en la variable amazónica. Desde la antropología es fundamental el texto de Hugo Niño, Primitivos relatos contados otra vez (1976), que reúne y recrea varios relatos míticos amazónicos. Es interesante el artículo de Camilo Vargas (2013) que sigue las coordenadas del río para estudiar la obra de tres escritores indígenas de la Amazonía colombiana, Hugo Jamioy Juagibioy (camentsá), Anastasia Candre Yamacury (uitoto) y Alba Lucía Cuéllar (tikuna), aunque sin leerlos como un repertorio poético particular (en tanto modelos de textos) de la producción amazónica, sino en su grado de relación con la tradición oral y mítica. 8 La primera etapa de la producción poética amazónica de Iquitos, en la década del 40, de carácter tradicional, es signada por los estudiosos centralistas como regionalista y folclórica, de estampas costumbristas, como fue el grupo Trocha, dirigido por Francisco Izquierdo Ríos, a quien se le reconoce el valor inédito de vincular lo andino con lo amazónico. Siguió a este grupo, con un carácter de transición entre lo tradicional y lo moderno, la revista Selva lírica, a fines de los 40, cuyo principal exponente es Germán Lequerica y consolida esta fase el grupo literario Bubinzana, en Iquitos, creado en 1963, integrado, entre otros, por Róger Rumrrill y Javier Dávila, en el que dejan de lado el viejo "selvismo y paisajismo" y comienza una etapa de experimentación textual y de confluencia temática entre lo social y lo mítico. 
publica su "Primer Manifiesto político-estético en donde buscaban cuestionar la realidad social vigente e interpretar artísticamente a la Amazonía". Los modos poéticos para ello fueron estrategias escriturales, mediante el uso particular del lenguaje que fijaba una manera de pensar y de sentir, pero desde la tensión de una lengua obliterada que releva las marcas de las estructuras sintácticas y gramaticales de las lenguas amazónicas que se cuelan en la aparente pureza del castellano. Estas actitudes lingüísticas estarían operando como estrategias de reterritorialización simbólica.

Por su parte, la poesía amazónica boliviana, de larga tradición, también experimentó la transformación poética, influenciada por hitos históricos como la Revolución Nacional del 52, la presencia del Che Guevara, las dictaduras militares (como sostiene Carvalho). En este contexto surgen corrientes literarias que están en la búsqueda de una renovación. Homero Carvalho ha señalado que

Trascendiendo la búsqueda de la identidad, ahora, los poetas profundizan en lo filosófico y en lo espiritual, así como en lo mundano, apuestan a un nuevo lenguaje y construyen su propia e íntima relación con el espacio y el tiempo. Lo amazónico ya no está presente simplemente como un tema, sino como una síntesis cultural, en la que los poetas encuentran su diversidad de voces y estilos. Voces y estilos que proyectan una nueva forma de pertenencia, una nueva identidad social, política y cultural, propias del sujeto histórico (26).

Los poetas emergentes se desprenden de los firmes sellos de las generaciones anteriores, pero sin dejar de reconocer las deudas y padrinazgos de autores emblemáticos, como los reunidos en la antología Poetas del oriente boliviano, de Pedro Shimose.

\section{Estrategias de reterritorialización en la poesía amazónica}

Desde un marco teórico nos interesa la noción articuladora de territorio (Escobar) ${ }^{9}$ y sus derivados, territorialización, desterritorialización y, particularmente, reterritorialización (Deleuze 1997 y Maíz 2010), como procesos concomitantes y fundamentales en los contextos de interferencia cultural, experiencias que testimonian los autores del corpus. Para Claudio Maíz, los cambios en los diseños imaginarios de la territorialidad "implican alteraciones en los paradigmas identitarios", reconociendo una relación directa entre alteridad y espacio. Esta relación no se expresa únicamente en el nivel político del territorio, sino que también "afecta la vida doméstica" (Marc Auge, 1993). La reterritorialización se manifiesta por el desplazamiento migratorio

\footnotetext{
9 Escobar distingue entre territorio y territorio-región. El primero es entendido "como el espacio de apropiación eficaz de los ecosistemas por una comunidad dada, mientras la noción de territorio-región de grupos étnicos se consideró como una construcción política para la defensa de territorios. Si el territorio encarna el proyecto de vida de la comunidad, el territorio-región articula el proyecto de vida de la comunidad con el proyecto político del movimiento social" (2010: 73).
} 
poblacional, cuyo resultado son procesos de ajuste simbólico entre lo extra, lo inter y lo intracultural, donde entra en juego la memoria, el problema de la lengua, la recuperación y la actualización de las tradiciones, entre otros aspectos. Como estrategia la visualizamos a nivel simbólico y geográficogeopolítico. En el plano simbólico, el sujeto se constituye en referencia a los símbolos de la cultura, que pueden concebirse como objetos cotidianos que se relevan simbólicos en el uso (Foerster, 2000). En el plano geográficogeopolítico es la construcción de un tercer espacio o la recuperación del propio espacio; sin embargo, un espacio modificado, produciéndose lo que denomina Manuel Dammert (2008) una dialéctica del territorio o una dialéctica del lugar, producto de migraciones, políticas extractivas y otras problemáticas que generan procesos de subintegración ${ }^{10}$ desde las transformaciones del espacio geohistórico (Pedro Cunill, 1995). El planteamiento inicial es que a partir de la experiencia de desterritorialización y desplazamiento, el sujeto poético amazónico se reconstruye desde claves de reterritorialización que operan mediante dos procesos (la recuperación intracultural y el agenciamiento intercultural), que funcionan como instancias de validación de una identidad colectiva, y que generan, sin embargo, distintas actitudes enunciativas, gracias a diversas estrategias que hemos identificado como la reescritura de la (micro) historia o de acontecimientos, la apelación a lo sagrado, la rememorización y la apropiación del lenguaje (vinculada a las actitudes lingüísticas).

1. La reescritura de la (micro) historia o de acontecimientos. Este procedimiento rescata la relectura y reescritura (desde una óptica poética) de sucesos "que las comunidades han considerado como marcadores de su historia" (Foerster 2000: 89). Se recrea una atmósfera destinada a desentrañar acontecimientos desconocidos, que se han querido borrar o que se han mostrado desde la historiografía oficial visibilizando la otra historia, el "revés de la arpillera". Se trata de comprender el pasado en el presente. Este procedimiento fija la atención en la relación entre el modo de pensar la memoria individual, dual o colectiva y de escribir la historia. Un leitmotiv de esta producción es la visión crítica de la versión oficial de la conquista y la restitución de su historia verdadera. Veamos algunos ejemplos. María Clara Sharupi, de la nación Shuar de Ecuador, escribe en el poema "Como Nantar y Namur":

Dedos mutantes que trajeron los conquistadores / pretendieron confeccionar mi destino / como el águila me deslicé bajo la piel del viento / jíbara fue el nombre con el que me latiguearon / ráfaga de municiones y pólvora fue la semilla en mi corazón / tomaron para la corona

\footnotetext{
10 Ismael Vega (2013), a propósito de los migrantes indígenas amazónicos en Lima, señala en Buscando el río: "La migración indígena amazónica está históricamente marcada por relaciones asimétricas de poder y exclusión ( ) Los migrantes indígenas amazónicos tienen diferentes orígenes pero comparten una situación caracterizada por las malas condiciones de vida, la amenaza y violación a sus derechos individuales y colectivos ( ) Además de la discriminación cultural los migrantes indígenas amazónicos viven una discriminación estructural que los coloca en el último lugar de la estratificación social" (103-104).
} 
española / los más sagrados manjares para calmar su sed de piedra muerta.

En estos versos la sujeto poética en un gesto de resistencia cultural se ve en la necesidad de contar, testimoniar y restituir la historia (verdadera) de los shuar, como un ejercicio de reapropiación intracultrual. A pesar del trauma de la conquista en que pretendieron modelar su destino, logra ella escapar con el conocimiento que tiene de su territorio y "como el águila deslizarse bajo la piel del viento". Un texto de la misma factura crítica es el poema "En la espesura" de Ana Varela, que da cuenta de la ininterrumpida historia de exterminio en la Amazonía peruana y en particular de los pueblos bora y uitoto de las riberas del río Ampiyacu:

Arrastrados por episodios de exterminio los peones arrojados hacia los bosques fueron alcanzados por la sangría.

Algunos moradores escucharon disparos en el aire mientras bajaban por extraños ríos de miedo

La madrugada crecía en las matanzas y las abuelas descifraban caminos en la intemperie

Las muchachas del Ampiyacu lloraban el fin del mundo y sus pies semejaban sierpes vespertinas en los barrancos

Huyendo espantados por las infamias, ahora todos, casi todos, somos fragmentos de pueblo en la espesura.

El poema revisa la historia de exterminio y de los sistemáticos abusos de las culturas indígenas de la Amazonía peruana, desde la experiencia compartida, vital, angustiosa y crítica de la pérdida sostenida de referentes de su vida cotidiana. La huerfanía es la actitud de la voz poética colectiva, provocando una nueva forma de extrañamiento que se manifiesta en el tono elegíaco del poema. La ausencia de su lugar en una situación de migrancia, éxodo, diáspora o desplazamiento, provoca en la sujeto, de manera forzosa, el traslado de un espacio de cobijo a otro incierto, experimentando la incomprensión de los nuevos espacios en que se agudiza un sentimiento de pérdida ("somos solo fragmentos de pueblo en la espesura"). También la reescritura de acontecimientos que son marcadores de la historia la encontramos en textos que cuestionan no solo la empresa de la conquista, sino también la espiritual y la colonizadora, como la llegada de europeos tras las riquezas de los recursos naturales, el caucho entre ellos, como se puede ver en el poemario Santuario de peregrinos, del escritor Percy Vilches, texto que traza una línea de tiempo que parte a fines del siglo XVIII hasta nuestros días y que reescribe acerca de personajes o hechos históricos como "el arribo del obispo", "Una curandera en prisión (1938)" acusada de brujería, el incendio del cine ("Después del incendio en la Alhambra"). Consideremos en este sentido el poema "Inicio del éxodo": 
Desde Londres vino la nave de la distancia desconocida,/ de otro mundo $/(\ldots)$ a las 5 de la tarde apareció como un monstruo sobre las aguas (...) / eran los carnavales de 1864, la nave venía de naufragios / y traía implementos para armar una villa / de comercio y casinos, de contrabando y baratijas, / de usura y putería. / Entonces aparecieron extrañas casas como muros del mal (...) / los indios cortaron leñas, construyeron ramadones / para atender a los marinos, los operarios ingleses. / Las calles cambiaron de nombres, de ocupantes / y se hicieron los nombramientos oficiales /(...) El barrio de los Iquito desapareció / Comenzó entonces la huida, la marcha forzada, / el éxodo que duró más de un siglo / hasta volver a las praderas del río Nanay".

En el texto se puede advertir cómo se ve modificado su propio espacio con la llegada de los ingleses, situación que altera para siempre la fisonomía del paisaje con la extracción del caucho. Los nuevos colonos instalan y construyen un pueblo a imagen y semejanza de una ciudad europea, desarticulando la forma de vivir de una cultura que se ve desplazada, deslocada, desterritorializada, huérfana.

2. La apelación a lo sagrado. La pérdida de referentes genera mecanismos compensatorios, en la búsqueda de un territorio (geográfico o simbólico) por habitar. Ello se logra por medio del dialogismo, la construcción homomórfica de sus propias tradiciones y manifestaciones etnoculturales o la alusión a símbolos sagrados. Como ha reconocido Mabel García (2006), la "aproximación al mundo ancestral es un intento de reterritorialización simbólica de la cultura, instauración de un espacio y tiempo que se extiende sin límites desde la atemporalidad propia de la relación mito, rito y sueño". Un modo en que puede presentarse esta estrategia es la reconstrucción homomórfica, entendida como un simulacro formal, (re)escritura que asemeja la estructura textual del mito de origen y que permite su actualización, lo que ha denominado Jorge Lora reidentificación o Mabel García retradicionalización, pero también la resignificación del mito mediante el recurso de la ironía y la parodia. Este es el caso del poemario de Percy Vilches, El andante de Yarinacocha, organizado en cuatro orillas, la primera de estas utiliza la estructura del relato mítico, como el poema II:

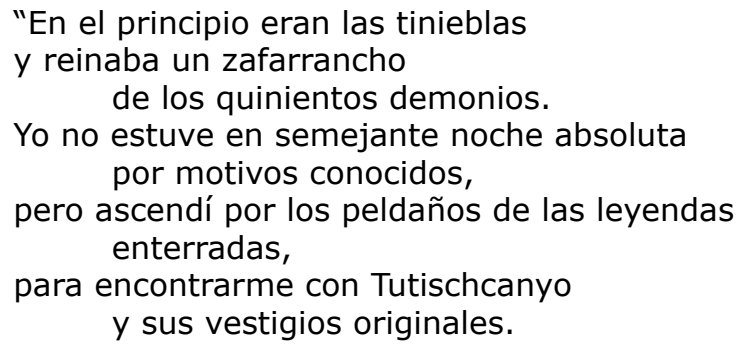

El texto, en una aparente reconstrucción mítica, aprovecha la similitud textual para invertir y desacralizar el sentido original del relato con el uso coloquial de la lengua. En el libro el sujeto navega por la laguna de Yarinacocha, 
de forma circular por las cuatro orillas, en un viaje que parte y culmina en la experiencia de un hablante poético shipibo conibo que ve cómo se va perdiendo y trastocando con el tiempo el sentido de los elementos culturales; nombrarlos y reconstruirlos es un modo de mantenerlos vivos. El texto también reconstruye de manera homomórfica las imágenes que reproducen la simbología del arte shipibo, el kené. Al igual que el relato mítico, el discurso visual apela a la recuperación del sentido de este arte y critica la imagen mercantilizada que se le ha dado, en tanto signo vacío.

También utiliza el recurso de la construcción homomórfica el poeta boliviano Homero Carvalho, quien reescribe el mito de origen de primera creación en su libro Los Reinos Dorados "Cuando vivíamos / en los Reinos Dorados / el mundo no había nacido aún / existía la vida / existía la muerte / pero el mundo no había nacido aún / Nosotros / habitantes de la selva / asistimos al nacimiento / de ese mundo dorado/ donde todo era nuevo / donde todo era asombro / y ante todo estaba el Agua / el río / la lluvia ..."

Otra modalidad corresponde a la presencia de símbolos sagrados, como elementos cruciales de resistencia cultural, en tanto conocimiento particular de objetos que se tornan sígnicos en el contexto de su cultura. Se manifiestan mediante ciertos guiños a la oralidad, la tradición, los ritos, los sueños. Este es el caso del poema "El Yagé", de Anastasia Candre, okaína-uitoto, de Colombia, que alude a la planta, también conocida como ayahuasca, y que para su pueblo se torna sagrada, por lo que se utiliza en diversos ritos ancestrales entre las comunidades étnicas del piedemonte andino amazónico:

Yo soy el yagé / Nadie puede decirme quién soy / Soy tu abuelo boa / Así me presento / Mi presencia es miedosa / Yo soy el yagé / También, soy como el jaguar, que me siento, con mi piel pintada / No te asustes de mi presencia / iAbrázame! / Solo es un sueño / No me diga, ¿quién eres? soy el abuelo yagé / Soy el espíritu que permanece de pie / Yo soy la sanación / El dios de los sueños maravillosos / Cuántas enfermedades he quitado con mi soplo / Mi palabra es de vida y de saberes / Maldigo aquellas personas burlonas/ Si me piden perdón, perdono / He existido desde un principio / Y ningún ser se burla de mí / Yo soy el bejuco de la ciencia de los saberes / De mí, mi gente tuvo conocimiento / Soy el dios yagé.

En este poema el grado de identificación con la cultura es tal que su voz se torna ventrílocua del espíritu del dios yagé; el símbolo sagrado toma la palabra, en una actitud apostrófica. El Yagé opera en este caso no solo como vehículo para entrar en trance, sino como dios que va sanando y que interpela y seduce al sujeto en el estado alterado de conciencia en que se encuentra (No te asustes de mi presencia / iAbrázame!). El poema describe la situación ritual (la presencia de los animales sagrados como la serpiente y el jaguar, los sueños) y el origen atávico (He existido desde un principio). Otro ejemplo de alusión a los símbolos sagrados es el poemario Las hojas del poder. Relatos acerca de la coca entre los uitotos y muinanes de la Amazonía colombiana, de Fernando Urbina, como en "Yo siembro coca": 
Yo, / Aprendiz de la palabra - Hoja del Padre, / Siembro mi coca; / Ella tendrá la Fuerza: / El poder que confiere la Palabra Origen, // He tumbado la selva, / He despejado el terreno, / Igual hice con mi espíritu: / Lo aireé con las Palabras - Aire del Origen, / Suavicé la tierra de la siembra, / Deshice los terrones. / El Abuelo me ha dado / el arbusto viejo de su chagra antigua. / Con sus palabras vetustas, ya cansadas / urdiré las nuevas de la Obra / y sobre ellas tramaré mi vida./ Ya mi tierra está lista/ ya mis cuidados la semilla / - de la gastada planta- / se cubrirá de hojas, de renuevos fuertes. / Así comenzaré el ciclo que es mi historia. / Algún día mi Palabra - Hoja / remozará su Fuerza entre mis hijos.

Mediante el recurso de la imagen se muestra en paralelo el paso a paso de la preparación de la tierra para el cultivo de la planta de coca, pero también del modo en que prepara su espíritu para ser digno de ese acto sagrado; de este modo el sujeto poético actualiza el rito y la función simbólica y metafórica (la Palabra-hoja) que ella representa; reapropiación intracultural que proyecta con sus renuevos, el ciclo de su vida y su historia.

Ana Varela recoge en su escritura una identidad de ascendencia de la cultura amazónica cocama. La asunción de una voz propia indígena permite a la sujeto poética identificarse con las construcciones cosmocéntricas presentes por ejemplo en los símbolos sagrados, por medio de los guiños a los referentes naturales y culturales, como en el poema "Breve Paisaje", del libro Voces desde la orilla: "Piel de sierpe, cruz de mashco, sueños de garza, lengua o aletas de renaco: ¿quién enumera este / trazo de mi cuerpo abierto a cielos despejados? / Porque las pintas me inundan en las tahuampas y así he sido siempre albedrío de un río que despide voces de agua en cauces solariegos / Peje inadvertido siempre aquí pinta de hembra contando en playas no tocadas los granos de arena / asesinados por los barcos". La sujeto describe este breve paisaje como si estuviese haciendo el ejercicio de la écfrasis respecto de una pintura cocama, como "el ojo que cuenta"11 imágenes que retrotraen a la patria del agua, fauna y flora particular de la selva baja amazónica (tahuampas). La sierpe es un animal simbólico para las culturas amazónicas, está presente en sus mitos fundacionales y es la encargada de mediar el trance en la toma de ayahuasca. En el texto la serpiente es la propia hablante en un hábitat acuático amenazado por los embates de los nuevos sistemas depredadores de la selva, representados por los barcos que extraen la materia prima. Un último ejemplo de esta estrategia de apelación a los elementos simbólicos es la alusión al espacio que se torna sagrado para el hablante en "Mi sagrado lugar", de Hugo Jamioy, poeta colombiano del pueblo kamëntsá:

Quiero llorar / pero que el agua / que brotará de mis ojos / no caiga en cualquier lugar / quiero que la recoja / la

11 Título de una publicación de divulgación de las cosmovisiones de los pueblos amazónicos:

El Ojo que cuenta, Mitos y costumbres de la Amazonía indígena, ilustrados por su gente. 
Madre que me brindó la cuna / donde guardó las primeras / gotas de mi existir. / Quiero llorar / en el lugar que lloraron mis abuelos. / Quiero llorar / en el sagrado lugar / donde los padres de mis abuelos/ no sabían qué era llorar. // Quiero llorar / porque mis padres me heredaron / un lugar donde pueda hacerlo. / Quiero llorar / y quiero que mi hijo aprenda a llorar; / pero que no llore / sino hasta cuando / le herede a Tsebatsana Mamá / (Madre Responsable/Madre Tierra) / y tenga su territorio donde llorar. // Y ustedes saben llorar? / Tienen dónde llorar?

El poema concentra todos los tiempos, pasado, presente y futuro, esta "compleja temporalidad", al decir de Jelin, para quien "los sentidos de la temporalidad se establecen de otra manera: el presente contiene y construye la experiencia pasada y las expectativas futuras" (2002: 12). En el poema, la alusión al futuro "el agua que brotará de mis ojos" no es sino la prolongación de sus ritos y de su forma de vivir que viene desde los padres de sus abuelos y que él quiere preservar para sus hijos. Sin embargo, lo que traspasa las generaciones es el llanto, signo de sufrimiento que comenzó con sus abuelos. En una clara correlación histórica nos percatamos que fue la generación que padeció el trauma del choque cultural. La restitución de ese espacio como lugar sagrado ("donde los padres de mis abuelos / no sabían qué era llorar") es un modo de reterritorialización y reapropiación intracultural de resistencia y cobijo identitario en proyección para sus hijos y los hijos de sus hijos.

3. La rememorización. Es la resignificación de la memoria por medio de los textos poéticos, traducida en la articulación de una nueva propuesta discursiva. Tres son las propuestas teóricas que pueden dialogar para revisar este procedimiento. Rolf Foerster (2000) desde las nociones de tiempo de lo cotidiano / de la memoria y los elementos simbólicos, Elizabeth Jelin (2002) con los trabajos de la memoria, y su relación con la identidad y Pierre Nora (1986) con los lugares de la memoria.

La rememorización es una estrategia más propia del agenciamiento intercultural, de localización subalterna (Escobar, 2010). El sujeto migrante conjuga simultáneamente el tiempo de la memoria (la nostalgia) y el tiempo de lo cotidiano donde se cuela el tiempo de la memoria para rescatar sus susurros, que si bien son fragmentos, permiten a quien lo vive "que su estar cuaje en el ser". En el caso de la poesía amazónica la experiencia migrante tiene una imagen nítida de lo que se añora desde esa memoria que se filtra en el presente: Ios cauces fluviales; para Ismael Vega será el sujeto "buscando el río"12. Una clara muestra de la superposición de ambos tiempos son los

\footnotetext{
12 Buscando el río es el título de un libro que muestra cómo se va reinventando lo amazónico en la ciudad de Lima, "los migrantes indígenas amazónicos tienen en la pertenencia étnica el referente más importante para reinventar sus identidades y establecer sus relaciones sociales. Compartir un pasado común y la conciencia de pertenencia a un mismo pueblo y un mismo territorio son elementos que siguen vigentes en la ciudad" (50). Todos expresan y reivindican abiertamente su identidad étnica cultural, ningún migrante ha buscado ocultar su identidad. Los indígenas amazónicos consideran que la identidad étnica es un factor fundamental en su estrategia para insertarse en la ciudad (104).
} 
versos de Juan Carlos Galeano, poeta colombiano que vive en el extranjero: "Cerrar los ojos y ser dueño / repentino de cursos fluviales. / Liberarse de entumecidas vigilias / y sentir selvas aquerenciadas". También el peruano Alfredo Pérez Alencart, radicado en España, en distintos pasajes y de manera recurrente se referirá a esta imagen que lo acuna "Cerremos los ojos. / Retrocedamos a la imborrable juventud / que pertinaz desemboca / en el inagotable caudal del Madre de Dios". "Estimados paisanos: caben en mi memoria todos los recuerdos / que suavemente sostienen el paisaje indesteñible / del puerto fluvial que todavía observo / con los ojos de la infancia"...

En estos ejemplos podemos advertir un sujeto proactivo en los procesos de transformación simbólica y de elaboración de sentidos del pasado, que trabaja la evocación desde su accionar (cerrar los ojos, liberarse, retroceder...), por tanto la palabra se constituye en acto de habla, en esa acción perlocutiva que hace en el decir. Este accionar le da sentido y espesor a una identidad que comienza a trazarse desde la memoria:

La memoria tiene entonces un papel altamente significativo, como mecanismo cultural para fortalecer el sentido de pertenencia a grupos o comunidades. A menudo, especialmente en el caso de grupos oprimidos, silenciados y discriminados, la referencia a un pasado común permite construir sentimientos de autovaloración (Jelin, 2002: 9).

El migrante, si bien necesita ese tiempo de la memoria, debe sentir que pisa tierra firme en el tiempo de lo cotidiano, que logra agenciarse en ese tercer espacio. El agenciamiento, no obstante, como etapa de culminación de la instalación en otro territorio, supone etapas de transición desde el trauma del desprendimiento y el desarraigo de su terruño, pero también de la ajenidad en el nuevo espacio. Nicomedes Suárez en "Apuntes y observaciones del diarista de Loén" escribe: "Estoy cansado de reconocerme en los espejos de otras tierras! A momentos solo soy un fragmento, un brazo o quizá un torso, muelles donde me derramo como trigo y zarpo, encerrado en mí mismo". Una experiencia similar es la del sujeto poético en Alfredo Pérez, cuando dice: "Llueve y sigo pisando recuerdos. / Enseño lastimaduras cuando el cuerpo levita / sobre un tapiz esmeralda / que cifra aquilatadas bienvenidas. / Transterrado de tan inmenso reino, / tropezando, / a saltos de aire, / voy volviendo a lo que es mío".

El tiempo de la memoria utiliza los sentidos para hacerse presente. Esto se observa en los versos de la poeta Shuar de Ecuador María Clara Sharupi, donde el olfato es un potente generador de recuerdos: "la envoltura que me cobija / no es el tarach-i que tejió mi madre nunkui / tampoco es la piel de Shakaim / ni su sangre hecha color / sin embargo / el perfume que me adorna / seduce mis instintos y despierto cobijada por los brazos de Arutam". Los elementos culturales ya no son los mismos en su nuevo espacio, pero al menos puede recordarlos y religar su sentido de pertenencia y permanencia; "poder recordar y rememorar algo del propio pasado es lo que sostiene la identidad" (Jelin: 2002: 25). La experiencia migrante en Sharupi ha hecho que tome conciencia de su rol protagónico en la preservación de su cultura, como ha señalado en Los desafíos de la Mujer Shuar 
desde su origen: "La participación y el verdadero desafío de la mujer shuar está más allá de ser una copia del mundo occidental, el verdadero desafío y la resistencia están en nuestros espíritus, con la misma sabiduría que heredamos de nuestros ancestros".

La rememorización se constituye también en referencia a los símbolos de la cultura (Foerster), que pueden concebirse como objetos cotidianos que se relevan simbólicos en el uso. Tal es el caso del poema "Árbol" del boliviano Nicomedes Suárez, que comienza con una dedicatoria: A Jesús Urzagasti y Pedro Shimose, amantes de los bosques:

Se mezcla masa de pan / y agua hasta que sea / una masa más o menos blanda.

Cuando está pronta / se agarra un gajo duro de un relámpago / que sea resistente

y en bonita forma / y se lo va paralizando... / La masa está pronta, / cuando echándole agua

ya no la absorbe. / Tiene que llevar formas / Irregulares con sobresalientes, / así como Iquitos, Leticia, Riberalta, / Manaus o Belém / se elevan en la selva / sobre el nivel de las aguas.

Después que se baña el gajo / Íntegramente, se coloca / al sol y entre lianas de lluvia

por doce mil años. / Entonces se le añaden, / poco a poco, la corteza / de los pueblos circundantes

En este hermoso poema la imagen del árbol, objeto cultural universal, se torna simbólico en el contexto de la región amazónica, o mejor dicho panamazónica. El árbol ya no es solo una "planta de tronco leñoso, grueso y elevado que se ramifica a cierta altura del suelo formando la copa", sino un objeto simbólico que concentra una cosmovisión holística, en una relación simbiótica y consubstancial de todos los seres y elementos naturales y culturales que habitan la región.

En una dimensión similar encontramos la propuesta de Pierre Nora, de los lugares de la memoria, desde donde se asume que un objeto (elemento cultural o natural) o acontecimiento se transforma en un elemento simbólico cuando la memoria individual actúa; es decir, los objetos de la vida cotidiana pueden ocasionar o restaurar el recuerdo, y desentrañar su verdad simbólica más allá de su realidad histórica. Los objetos pueden ser simples lugares, materiales, ceremonias, emblemas, entre otros. La gama de objetos posibles es, de hecho, infinita. Todo radica, señala Nora, en hacer aparecer "la imagen en el cuadro", un fragmento simbólico de un conjunto simbólico. El poeta colombiano Juan Carlos Galeano, ha comentado en una entrevista "para mí las narrativas orales de los amazónicos nacen a partir del protagonismo que tienen todos los seres de la selva. El quebrarse de una rama, una ráfaga de viento, las sombras que hacen las hojas, los signos en el agua; todo sugiere interconectividad cósmica". Un ejemplo poético de este procedimiento es el poema Salsa de Ají de Nicomedes Suárez: "Se añaden sal y pimienta / a una cucharada de ají amarillo molido / con una cucharada rasa de pesares. / Se pone sobre el sueño / como se pone 
mantequilla al pan. / Después de sacar del sartén / a las fragatas invasoras / se pone caldo o agua. / Se hace dar un hervor / y se vacía como un grito / entre los vivos y los muertos". El ají, elemento natural, propio del sistema culinario amazónico, opera como sinécdoque, en tanto fragmento simbólico de un conjunto simbólico. El ají despierta en el sujeto una sensibilidad que pone en crisis dos sistemas culturales y provoca en el presente el trauma histórico. Otro texto en que los objetos se transforman en elementos simbólicos cuando la memoria individual actúa lo encontramos en Francelina Muchavisoy Becerra (tamia wawa) de la Amazonía colombiana, del pueblo Inga: "El tambor será mi casa / la cuna la canoa / el remo mi futuro / el río mi camino / la selva la ciencia / la tierra la base / el sol mis alcances / el aire mis pulmones / la sangre la savia". Los objetos a los que alude le son suficientes (y por eso la condensación lingüística, las elipsis) para la mantención de su cultura. Si bien esta memoria es individual de una sujeto, contiene también la visión del mundo enmarcada socialmente.

4. La apropiación del lenguaje (vinculada a las actitudes linguiísticas); este procedimiento se vale del lenguaje (memoria) del otro, para revestirse con él. Se relee y refunda un pasado desde el lenguaje del otro, lo que genera distintas actitudes enunciativas, tanto si ese lenguaje del otro lo contiene a él o, si al revés, él contiene al otro mediante su lenguaje, o si se presentan las voces simultáneamente, como una polifonía discursiva. Las marcas textuales pueden ser el uso de comillas y cursivas que simulan la voz alternada de otro sujeto poético, como la voz personificada de un antiguo pueblo amazónico en Carlos Reyes Ramírez: "Y se te ha visto, te han visto, hermoso Sinacay, / sobre los escombros de tu pueblo alejado: abierto / igual que un lagarto amado por los sables, / tumbado en las hojas que aventuraron tu memoria // "Nada, ni siquiera las aves que presagian / el destino logran tocarme, ni las estrellas rojas / ni las vírgenes feas que presenciamos / desde una voraz tormenta de fuego. Nada pudo / atraerme a sus tablones pendencieros". El poeta cede la voz a otro sujeto al que no le quedan sino escombros y la voz fuerte de resistencia, actitud defensiva cuya herramienta es la palabra y la selva impenetrable.

Por otra parte, en el estudio de la identidad lingüística, las actitudes forman parte sustancial de la explicación en torno a la competencia comunicativa del hablante (Vega, 2013), desde su lengua materna, como dirá Alfredo Pérez, donde "escuché el silabario de la cuna", pasando por las influencias de otras lenguas o variedades establecidas en el aprendizaje. Las actitudes lingüísticas explican además la forma con la que ejecutan la discriminación lingüística. De este modo, las actitudes lingüísticas se manifiestan hacia los usos propios del lenguaje, pero también, y como criterio de identidad, hacia los ajenos (López Morales en Vega 2013). Aquí operan mecanismos de valoración en torno a la lengua o su variedad en uso, mediante juicios inscritos en el discurso. Si bien la rememorización permite instalar estrategias de resistencia, el poeta puede optar, a propósito del uso del lenguaje, por enunciar no solo en pasado, sino también en futuro, como una voz fuerte y profunda que quiere dejar huella, en el doble sentido de grieta, de hondura, pero también de camino que se abre. Veamos un ejemplo de la poeta colombiana de la cultura inga, Francelina Muchavisoy Becerra: "volveré a soñar mejor que ayer / caminaré cada rincón de mis sueños / 
navegaré la vida / volaré los cielos / cultivaré historias / viviré mi pueblo / viviré soñando / soñando moriré".

\section{Para concluir}

¿Qué me detiene aislado en esta tierra abandonada por los hombres, poseído y desgreñado por los pájaros insolentes que golpean mi cabeza?

Carlos Reyes Ramírez

Hemos hecho una lectura relacional en el campo de la poesía amazónica contemporánea, fijando la atención en la conciencia de desterritorialización y desplazamiento de los sujetos poéticos, que generan distintas estrategias de reterritorialización como una forma de resistencia cultural, entre las que hemos identificado la reescritura de la (micro) historia o de acontecimientos, la apelación a lo sagrado, la rememorización y la apropiación del lenguaje (vinculada a las actitudes lingüísticas). Estas estrategias no pretenden encasillar a los poetas y sus textos, sino revisar los mecanismos de reterritorialización que operan, a nivel discursivo, como metáfora de la revitalización de las distintas apuestas poéticas (en plural) en la región de la panamazonía.

La noción que nos ha permitido articular la actitud enunciativa con la dimensión territorial, es la de apropiación, entendida en este caso tanto como la reapropiación del espacio propio, agenciamiento no solo de ciertos elementos y estrategias que permiten construir desde este conjunto un nuevo tipo y estilo de enunciados, sino también como la apropiación de un espacio, dimensión territorial, desde su cultura hacia la cultura en contacto. De la revisión de los textos poéticos y de la lectura de varias posibles categorías teóricas, hemos finalmente propuesto nociones que cooperan para la configuración simbólica y geográfica-geopolítica en el proceso de reterritorialización desde la reapropiación intracultural y el agenciamiento intercultural del sujeto migrante.

\section{Obras citadas}

Augé, Marc. 1993. "Espacio y alteridad". Revista de Occidente, n. 140: 13-34. Ayala Olazával, José Luis. 2011. Diccionario de la cosmopercepción andina. Lima: Arteidea.

Brown, Michael. 1984. Una Paz Incierta: Historia y Cultura de las Comunidades Aguarunas Frente al Impacto de la Carretera Marginal. Lima, Perú: CAAP.

Carvalho, Homero. 2013. Los tres cielos, Antología de la Poesía Amazónica de Bolivia. La Paz: Editorial 3600.

Cunill, Pedro. 1995. Las transformaciones del espacio geohistórico latinoamericano, 1930-1990. México D.F: FCE.

Dammert, Manuel.2008. Dialéctica del territorio/Esquizofrencia del lugar. Lima: UNMSM.

Deleuze, Gilles y Felix Guattari. (1997). Mil Mesetas. Capitalismo y esquizofrenia. Valencia: Pre-Textos. 
Descola, Philippe. 1996. La selva culta. simbolismo y praxis en la ecología de los Achuar. Quito: Editorial Abya Yala.

Escobar, Arturo. 2010. Territorios de diferencia: Lugar, movimientos, vida, redes. Colombia: Envión Editores.

2014. Sentipensar con la tierra Nuevas lecturas sobre desarrollo, territorio y diferencia. Medellín: Ediciones UNAULA.

Espino, Gonzalo. 2011. "Letras indígenas: alegato y memoria de Ricardo Virhuez Villafane" (47-52). Letras indígenas en la Amazonía peruana. Lima: Pasacalle.

Foerster, Rolf. 2000. "La poética mapuche huilliche como procedimiento de rememorización". Pentukun 10-11: 55-70. Temuco: Instituto de Estudios Indígenas, Universidad de La Frontera.

Galeano, Juan Carlos. 2013. "La violencia ha marcado las actitudes de los poetas colombianos en varias ocasiones", entrevista de Mario Pera. (24 de junio) http://la-convencion. blogspot.cl/2013/06/entrevistajuan-carlos-galeano-la.html

García, Mabel. 2012. "El proceso de retradicionalización cultural en la poesía mapuche actual: Üi de Adriana Paredes Pinda". Revista Chilena de Literatura 81 (2012): 51-68.

2006. "El discurso poético mapuche y su vinculación con los 'temas de resistencia cultural'". Revista Chilena de Literatura. Abril 2006, Número 68: 169-197.

Gastó, Juan. 1993. Clasificación de Ecorregiones y determinación de Sitio y Condición. Manual de aplicación a municipios y predios rurales. Quito: Red de Pastizales Andinos, CIID-Canadá.

Guallart, José María. 1981. Fronteras vivas. Poblaciones indígenas en la Cordillera del Cóndor Editorial(es): CAAAP: Lima.

Jelin, Elizabeth 2002. Los trabajos de la memoria. Madrid: Siglo XXI.

Jemio, Lucy. 2005. Senderos y mojones: literatura oral aymara jukumarita. La Paz: Universidad Mayor de San Andrés.

Larochelle, Jeremy. 2012. Más aplausos para la lluvia. Antología de poesía amazónica reciente. Perú: Tierra Nueva.

Lora Cam, Jorge. 2004. Recolonización y Resistencia en el espacio andinoamazónico. Lima: Fondo editorial del Pedagógico de San Marcos.

Maíz, Claudio. 2010. Unir lo diverso. Problemas y desafíos de la integración Latinoamericana. Mendoza: UNCUYO.

Marticorena, Manuel. 2009. De shamiros decidores. Proceso de la Literatura Amazónica Peruana (de 1542 a 2009). Lima: Grupo Ed. Arteidea.

Niño, Hugo. 1976. Primitivos relatos contados otra vez: Héroes y mitos amazónicos. Editorial: Casa de las Américas.

Nora, Pierre (dir.) (1984-1992), Les Lieux de Mémoire (7 vols.). París: Gallirnard.

Pineda, Camacho Roberto. "La historia, los antropólogos y la Amazonia". Antípoda: Revista de Antropología y Arqueología. № 1, 2005, pp. 121-135.

Rocha Monroy, Ramón. 2013. "Poesía amazónica". Los tres cielos, Antología de la Poesía Amazónica de Bolivia. La Paz: Editorial 3600, pp. 17-18.

Rumrril, Roger. 2011. "La Amazonía y la nueva utopía social en el siglo XXI". Libros \& artes: revista de cultura de la Biblioteca Nacional del Perú. Lima: Biblioteca Nacional del Perú, año X, No 50-51, pp. 2-5.

San Román, Jesús. 1994. Perfiles Históricos de la Amazonía Peruana. Iquitos: CETA. 
Serje, Margarita. 1999. "La concepción naturalista de la naturaleza. Un desafío al ambientalismo". Revista de Antropología y Arqueología, vol. 1, No $1-2$, pp. 5-70.

Suárez Arauz, Nicomedes. 2014. "¿Existe una literatura amazónica boliviana?". Rev. Aportes de la comunicación. No 17, pp. 99-104.

Varese, Stefano. 2006. La sal de los cerros. Resistencia y Utopía en la Amazonía Peruana. Lima: Fondo Editorial del Congreso del Perú (primera edición 1968).

Vargas Pinto, Camilo. 2013. "Tras los ecos de la semilla. Una mirada a tres casos de la poesía indígena en Colombia". En Estudios de Literatura Colombiana, No 32, enero-junio, pp. 103-119.

Vega, Ismael. 2013. Buscando el río. Identidad, Transformaciones y Estrategias de los Migrantes Indígenas Amazónicos en Lima Metropolitana. Lima: Terra Nova.

Vega, Ricardo. 2012. Identidad lingüística y enunciación lírica en Choza de Efraín Miranda. Tesis Magíster en Literatura Hispanoamericana Contemporánea. Universidad Austral de Chile.

Virhuez, Ricardo. 2011 (1993). Letras indígenas en la Amazonía peruana. Lima: Pasacalle. 